Polymer Journa1, Vol. 2, No. 2, pp 148-152 (1971)

\title{
Polymerization of Methacrylamide Photoinitiated by trans-Diazidotetramminecobalt(III)Azide
}

\author{
H. Kothandaraman and M. Santappa \\ Department of Physical Chemistry, University \\ of Madras, Madras-25, India.
}

(Received September 25, 1970)

\begin{abstract}
The kinetics of polymerization of methacrylamide in aqueous solution photoinitiated by trans-diazidotetramminecobalt(III)azide was systematically studied at $35^{\circ} \mathrm{C}$ and $\mathrm{pH} \approx 3$. Monochromatic radiations of $\lambda=365,405$, and $435 \mathrm{~m} \mu$ were employed. The rate of monomer disappearance was followed bromometrically and the rate of complex disappearance spectrophotometrically. The effect of variables such as monomer concentration, light-absorption fraction by the complex, light intensity, and wave length on the kinetics was studied. The rate of polymerization was found to be proportional to the monomer concentration and independent of the light-absorption fraction $\left(k_{\varepsilon}\right)$ and light intensity $(I)$. A kinetic scheme consisting of (1) a primary photochemical act of excitation of the complex followed by electron transfer producing the azide radical, (2) initiation of polymerization by the azide radical, and (3) termination of the chain process by the excited complex molecules is proposed and discussed in the light of experimental results.
\end{abstract}

KEY WORDS Methacrylamide/Photopolymerization/trans-Diazidotetramminecobalt(III)/Monomer Disappearance/Complex Disappearance/Initiation/Termination/

Colour and complex formation have always been associated with transition metal ions. Most of the complexes show two distinct kinds of light absorption-the first chiefly in the visible having low intensity and the second kind in the ultraviolet having a much higher intensity ${ }^{1}$. Due to the ease of preparation and stability of cobalt complexes, they have been studied more extensively than other complexes. The intense band in the ultraviolet (CT band) is due to an electron transfer from the ligand to the metal. The CT bands for acidopentamminecobalt(III) complexes $\left[\mathrm{Co}\left(\mathrm{NH}_{3}\right)_{5} \mathrm{X}\right]^{2+}$ extend into the visible when the ligand, $\mathrm{X}$, is easily oxidizable. Thus when $\mathrm{X}=\mathrm{I}^{-}$or $\mathrm{N}_{3}^{-}$irradiation around $\lambda=370$ $\mathrm{m} \mu$ causes exclusive redox photolysis ${ }^{2}$. The ion-pair $\mathrm{Fe}^{3+} \cdot \mathrm{N}_{3}^{-}$was used as the photoinitiator $(\lambda>300 \mathrm{~m} \mu)$ for the polymerization of acrylonitrile, methyl methacrylate, and methacrylic acid indicating the presence of the azide radical $^{3}$. Azidopentamminecobalt(III)chloride was used as a photoinitiator for vinyl polymerization by Santappa, et al. ${ }^{4-6}$ Photopolymerization of acrylamide using chloro and aquapentamminecobalt
(III) complexes was studied by Delzenne. ${ }^{7}$ Polymerization studies involving tetramminecobalt (III) complexes, $\left[\mathrm{Co}\left(\mathrm{NH}_{3}\right)_{4} \mathrm{X}_{2}\right]^{+}$as initiators have been few. In this paper we present a systematic kinetic study of the polymerization of methacrylamide photosensitized by diazidotetramminecobalt(III)azide at different wave lengths (365, 405 , and $435 \mathrm{~m} \mu$ ) at $35 \pm 0.01{ }^{\circ} \mathrm{C}$ with a view to elucidating the nature of the primary process, subsequent dark reactions, nature of initiation and termination of polymerization and also to evaluate the various rate parameters.

\section{EXPERIMENTAL}

\section{Optical Arrangement}

For isolation of $\lambda=365 \mathrm{~m} \mu$ a high pressure mercury vapour lamp (125W, Mazda MBW/W supplied by B.T.H. Co., giving $99 \% 365 \mathrm{~m} \mu$ radiation) was used and for the isolation of other wave lengths $(\lambda=405$ and $435 \mathrm{~m} \mu)$ a high pressure mercury vapour lamp (250W; ME/D, box type, B.T.H. Co.) was used with suitable filter combinations $^{8}$. The light was rendered parallel by 
means of a biconvex lens. The reaction cell (light path, $4.6 \mathrm{~cm}$, diameter, $4.6 \mathrm{~cm}$ ) was a cylindrical vessel (capacity, $75 \mathrm{ml}$ ) fused at both ends with flat, optically clear, quartz plates and had two outlet tubes of standard B-14 cones for deaeration of the system.

\section{Preparation of the Complex}

Trans-Diazidotetramminecobalt (III) azide was prepared according to the method of Linhard and Weige ${ }^{9}$ and was found to be $99 \%$ pure, as shown by spectrophotometry $(\log \varepsilon=4.15$ at $\lambda=$ $337 \mathrm{~m} \mu)$. The cobalt content was determined according to Schwarzenbach ${ }^{10}$ (theoretical, 23.36; experimental, 23.32\%).

\section{Reagents}

Methacrylamide $^{11}$ (Rohm and Haas Co., U.S.A.) was purified by recrystallization by dissolving in a $4: 1$ mixture of benzene and ethanol, filtering the solution and cooling in ice. The solid was washed with cold benzene and dried at room temperature for about twelve hours under vacuum $\left(\mathrm{mp} 109.8^{\circ} \mathrm{C}\right)$. Potassium ferrioxalate, used for actinometry, was prepared ${ }^{12}$ from potassium oxalate and ferric chloride and purified by recrystallization from water. Perchloric acid (E. Merck, G.R., ca. $60 \% \mathrm{HClO}_{4}$ ) was used to maintain $\mathrm{pH}$. Solvents like methanol, ethanol, acetone, etc., were distilled immediately before use and middle cuts were used. Nitrogen freed from traces of oxygen by Fieser's solution ${ }^{13}$ was passed through to deaerate the reaction system.

\section{Estimations}

The purity and concentrations of the monomer were estimated by bromometry ${ }^{14}$. A typical experiment may be described as follows. The reaction mixture containing the diazido complex $\left(\sim 2 \times 10^{-5} \mathrm{~m} / l\right) ;$ monomer $\quad(\sim 0.1 \mathrm{~m} / l) ; \quad$ acid $\left(\mathrm{HClO}_{4}, \quad \mathrm{pH} \approx 3\right)$ and neutral salt $(\sim 0.1 \mathrm{~m} / l$, $\mathrm{NaClO}_{4}$ ) was taken in the reaction cell and deaerated for about $45 \mathrm{~min}$ in the dark. The reaction cell was then mounted in a thermostat at $35 \pm 0.01^{\circ} \mathrm{C}$ (maintained by a toluene regulator and hot-wire vacuum switch relay, Gallenkamp) in the path of the monochromatic light and irradiated for about $5 \mathrm{~min}$ depending on the concentration of the monomer. The rate of monomer disappearance was followed by determining the concentration of monomer (bromo- metrically) in the reaction solution before and after irradiation. The rate of disappearance of the complex was followed by the change in absorbancy of the reaction solution (measured in a UV spectrophotometer, Hilger \& Watts, Uvispek, $\mathrm{H}$ 700) after irradiation and reference to a Beer's law calibration curve for the complex at $\lambda=340 \mathrm{~m} \mu$. The intensity of light given by the mercury vapour lamp was determined by potassium ferrioxalate actinometry. ${ }^{12}$

\section{KINETIC SCHEME}

The following kinetic scheme appears to explain most of the experimental results.

(i) Light absorption and excitation of the complex

$$
\left[\mathrm{Co}\left(\mathrm{NH}_{3}\right)_{4}\left(\mathrm{~N}_{3}\right)_{2}\right]^{+} \underset{{ }^{+} \nu}{\stackrel{k_{\varepsilon} I}{\longrightarrow}}\left[\mathrm{Co}\left(\mathrm{NH}_{3}\right)_{4}\left(\mathrm{~N}_{3}\right)_{2}{ }^{*}\right]^{+}
$$

$k_{\varepsilon}$ is the light-absorption fraction by the complex and $I$ is the light intensity.

(ii) Dark-back reaction

$$
\left[\mathrm{Co}\left(\mathrm{NH}_{3}\right)_{4}\left(\mathrm{~N}_{3}\right)_{2}{ }^{*}\right]^{+} \stackrel{{ }^{k} d}{\longrightarrow}\left[\mathrm{Co}\left(\mathrm{NH}_{3}\right)_{4}\left(\mathrm{~N}_{3}\right)_{2}\right]^{+}+\Delta
$$

Deactivation of the excited complex in the dark leading to the complex molecule in the ground state, the excess energy, $\Delta$, being dissipated in the surrounding medium.

(iii) Redox-decomposition of the excited complex

$$
\begin{aligned}
& {\left[\mathrm{Co}\left(\mathrm{NH}_{3}\right)_{4}\left(\mathrm{~N}_{3}\right)_{2}{ }^{*}\right]^{+}} \\
& \quad \stackrel{{ }^{k} r}{\longrightarrow} \mathrm{Co}(\mathrm{II})+4 \mathrm{NH}_{3}+\mathrm{N}_{3}{ }^{-}+\mathrm{N}_{3}{ }^{*}
\end{aligned}
$$

(iv) Initiation of polymerization

$$
\mathrm{N}_{3} \cdot+\mathrm{M} \stackrel{k_{i}}{\longrightarrow} \mathrm{M} \cdot
$$

(v) Propagation of polymerization

$$
\begin{array}{r}
\mathrm{M} \cdot+\mathrm{M} \stackrel{\stackrel{{ }_{p}}{\longrightarrow}}{\longrightarrow} \mathrm{M}_{2} \cdot \\
\mathrm{M}_{2} \cdot+\mathrm{M} \stackrel{{ }^{k_{p}}}{\longrightarrow} \mathrm{M}_{3} \cdot \\
\mathrm{M}_{(n-1)}+\mathrm{M} \stackrel{{ }^{k_{p}}}{\longrightarrow} \mathrm{M}_{n} \cdot
\end{array}
$$

(vi) Termination by the excited complex

$$
\mathrm{M}_{n} \cdot+\left[\mathrm{Co}\left(\mathrm{NH}_{3}\right)_{4}\left(\mathrm{~N}_{3}\right)_{2}{ }^{*}\right]^{+} \stackrel{{ }^{k} t}{\longrightarrow} \text { Polymer }
$$




\section{H. Kothandaraman and M. Santappa}

\section{RESULTS AND DISCUSSION}

That the polymerization was free radical and photochemical in nature under deaerated conditions was shown by the existence of long induction periods $(\sim 30 \mathrm{~min})$ in the presence of oxygen and no evidence of polymerization in the dark. The steady state maximum rate was observed to be dependent on the wave length of light. The steady-state maximum rate $(\sim 12 \%$ conversion of monomer; $40 \%$ conversion of the complex) was attained in about $5 \mathrm{~min}$ at $\lambda=365$ and 435 $\mathrm{m} \mu$ and in $10 \mathrm{~min}$ at $\lambda=405 \mathrm{~m} \mu$. The solution was maintained acidic $(\mathrm{pH} \approx 3)$ in order to avoid precipitation of cobaltic hydroxide. All the experiments were conducted under deaerated conditions and at constant ionic strength $(\mu=$ 0.1 ). The effects of light-absorption fraction, light intensity, monomer concentration, wave length of light, etc., on the measurables, rates of monomer and complex disappearance were studied in detail.

\section{Rate of Monomer Disappearance $(-d[\mathrm{M}] / d t)$}

Making the usual assumptions for stationarystate kinetics for micro and macro radicals and non-variation of propagation and termination constants with chain length and on the basis of initiation by azide radicals and termination by the excited complex,

$$
\frac{-\mathrm{d}[\mathrm{M}]}{\mathrm{d} t}=\frac{k_{p} k_{r}[\mathrm{M}]}{k_{t}}
$$

The rate of monomer disappearance was found to be dependent on the monomer concentration (Figure 1) and independent of the light-absorption fraction and light intensity. These data

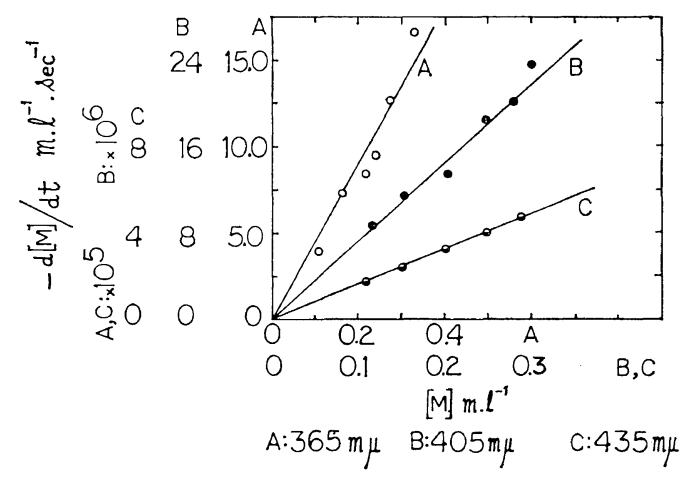

Figure 1. Plot of $-\mathrm{d}[\mathrm{M}] / \mathrm{d} t v s \cdot[\mathrm{M}]$. support the postulation of termination by the excited complex. If termination were by mutual combination the rate of monomer disappearance would have been dependent on $[\mathrm{M}]^{3 / 2}, k_{\varepsilon}^{1 / 2}$ and $I^{1 / 2}$. If termination were by azide radicals the rate would have depended on $[\mathrm{M}]^{2}$ and been independent of $k_{\varepsilon}$ and $I$. If the unexcited complex molecules had terminated the chains, the rate would have depended on $[\mathrm{M}]^{2}, k_{\varepsilon}$ and I. That the metal ions or their complexes can act as chain terminators by oxidising or reducing the polymeric radical is well known. ${ }^{15}$ Termination of acrylamide polymerization by chloropentamminecobalt(III) was proposed by Delzenne. $^{7}$ Natarajan and Santappa ${ }^{4}$ proposed termination by mutual combination in the polymerization of methacrylamide photoinitiated by azidopentamminecobalt(III)chloride. They explained the dependence of $-\mathrm{d}[\mathrm{M}] / \mathrm{d} t$ on $k_{\varepsilon}{ }^{0.25}$ and $I^{0.30}$ as being due to a mixed type of termination, i.e., by azide radical plus mutual on the analogy of observations by Toppet, et al. ${ }^{21}$ and Santappa, et $a .^{22}$ For the polymerization of acrylamide and acrylic acid initiated by diazidotetramminecobalt(III)azide $-\mathrm{d}[\mathrm{M}] / \mathrm{d} t$ was found to be proportional to $[\mathrm{M}]^{2}, k_{\varepsilon}$ and $I .^{23}$ These dependencies were explained on the basis of termination by the unexcited complex molecules. In contradistinction to the foregoing observations by others, our experimental results point to an interesting type of termination by the photoexcited complex. That mutual termination is unlikely in the case of methacrylamide polymerization may be inferred from the observations of Dainton ${ }^{16}$ that the propagation velocity of methacrylamide was much less than that for acrylamide, due to the steric strain conferred on the former by the substitution of a methyl group adjacent to the double bond. The probability of an excited complex interacting with polymethacrylamide radicals would therefore be higher than that of the interaction of two sterically unfavourable polymethacrylamide radicals for mutual termination.

\section{Rate of Complex Disappearance $(-d[\mathrm{C}] / d t)$}

The expression for the rate of complex disappearance on the basis of initiation by azide radical and termination by the excited complex would be 
Methacrylamide Polymerization by A Cobalt Complex

$$
-\frac{\mathrm{d}[\mathrm{C}]}{\mathrm{d} t}=k_{\varepsilon} I\left\{1-\frac{1}{\frac{2 k_{r}}{k_{d}}+1}\right\}
$$

The net quantum yield for complex disappearance, $\phi_{\mathrm{c}}$, would be equal to $\left\{1-1 /\left(2 k_{r} / k_{d}+1\right)\right\}$. The rate of complex disappearance was proportional to $k_{\varepsilon}$ or [C] (Figure 2) and $I$ (Figure 3)

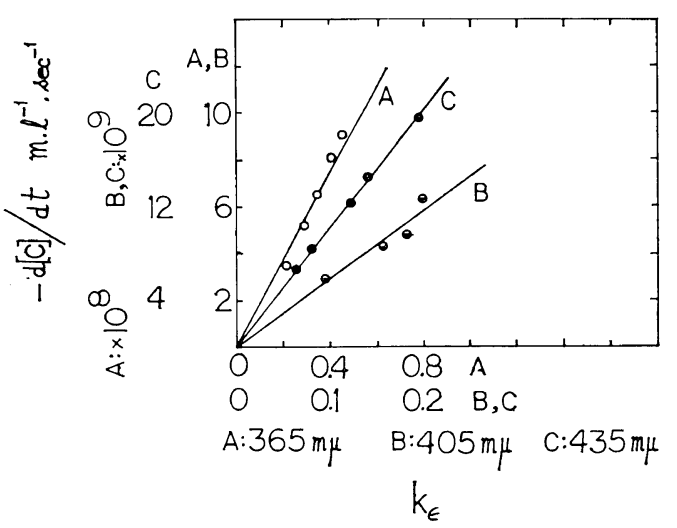

Figure 2. Plot of $-\mathrm{d}[\mathrm{C}] / \mathrm{d} t$ vs. $k_{\varepsilon}$.

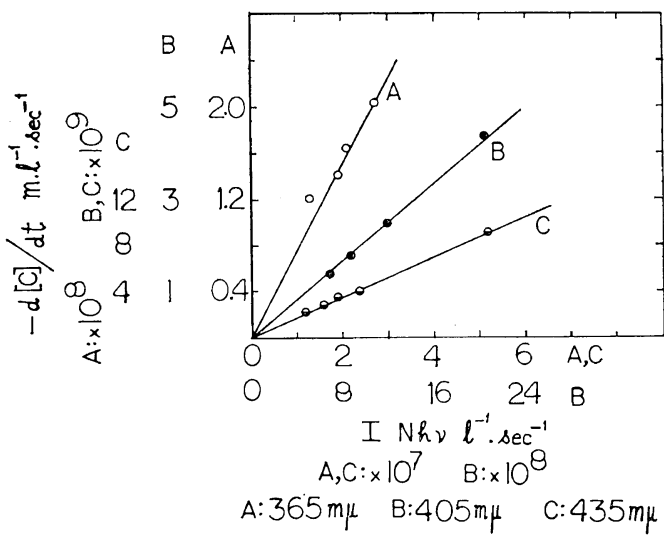

Figure 3. Plot of $-\mathrm{d}[\mathrm{C}] / \mathrm{d} t$ vs. I.

and independent of monomer concentration. The primary photochemical act that is postulated by us is excitation of the complex. The excited complex can in the dark undergo redox decomposition giving azide radicals or undergo deexcitation or terminate the chain process. Natarajan and Santappa ${ }^{4}$ during the study of the polymerization of methacrylamide photoinitiated by azidopentamminecobalt(III)chloride suggested the following primary step

$$
\begin{aligned}
& {\left[\mathrm{Co}^{\mathrm{III}}\left(\mathrm{NH}_{3}\right)_{5} \mathrm{~N}_{3}\right]^{2+}+h_{\nu}} \\
& \quad \stackrel{k_{\varepsilon} I}{\longrightarrow}\left[\mathrm{Co}^{\mathrm{II}}\left(\mathrm{NH}_{3}\right)_{5} \mathrm{~N}_{3} \cdot\right]^{2+}+\Delta
\end{aligned}
$$

The postulation of the existence of an excited state having a choice of a variety of reaction paths is more realistic in the light of recent knowledge of photochemistry. Valentine, Jr., ${ }^{17}$ observed that electronically excited states of moderately long life time-able to undergo internal conversion before reactive deactivationare intermediates in photochemical reactions of most cobalt(III) and other $d^{6}$ coordination complexes. He ascribed the inefficiencies observed in photoaquation and photoreduction of these systems to competing reactions of their electronically excited states and not to the recombination of radicals formed by primary homolytic cobalt-ligand bond fission as proposed by Adamson $^{18}$ and Wehry ${ }^{19}$. Another distinct difference in the kinetic scheme between the polymerization of acrylamide and methacrylamide is that radical scavenging by the complex molecule takes place in the former

$$
\begin{aligned}
& \mathrm{N}_{3} \cdot+\left[\mathrm{Co}\left(\mathrm{NH}_{3}\right)_{4}\left(\mathrm{~N}_{3}\right)_{2}\right]^{+} \\
& \stackrel{{ }_{k}}{\longrightarrow} \mathrm{Co}(\mathrm{II})+4 \mathrm{NH}_{3}+\mathrm{N}_{3}{ }^{-}+3 \mathrm{~N}_{2}
\end{aligned}
$$

That such a step was found unnecessary for the latter indicates that polymethacrylamide radicals preferentially combine with the excited complex and that the azide radicals exclusively react with methacrylamide molecules initiating polymerization.

Quanium Yields, $\psi_{\mathrm{c}}$

The primary photochemical act is the excitation of the complex molecule followed by the homolytic fission of the cobalt-azide bond to produce the azide radical. The formation of the azide radical was shown by the evolution of nitrogen in the absence of any monomer.

$$
\mathrm{N}_{3} \cdot(3 / 2) \mathrm{N}_{2}
$$

The operation of the Franck-Rabinowitch ${ }^{20}$ cage effect in preventing the separation of the fragments with decreasing energy of radiation is demonstrated by the decreasing quantum yields with increasing wave length of radiation (Table I). With increasing wave length the dark-back reaction of de-excitation $\left(k_{d}\right)$ becomes more important than the redox decomposition $\left(k_{r}\right)$. 


\section{H. Kothandaraman and M. Santappa}

Table I. Quantum yields at different wave lengths

\begin{tabular}{cccc}
\hline $\begin{array}{c}\text { Wave length } \\
\lambda, \mathrm{m} \mu\end{array}$ & $\frac{k_{p} \cdot k_{r}}{k_{t}}$ & $\frac{k_{r}}{k_{d}}$ & $\phi_{\mathrm{c}}$ \\
\hline 365 & $4.5 \times 10^{-4}$ & 0.182 & 0.27 \\
405 & $7.4 \times 10^{-5}$ & 0.135 & 0.21 \\
435 & $1.6 \times 10^{-4}$ & 0.123 & 0.20 \\
\hline
\end{tabular}

Natarajan and Santappa ${ }^{4}$ reported $\phi_{\mathrm{c}}=0.18$ (at $\lambda=365 \mathrm{~m} \mu$ ) for azidopentamminecobalt(III)chloride.

\section{Rate Constants}

The rate constants $k_{p} \cdot k_{r} / k_{t}$ were calculated from slopes of $-\mathrm{d}[\mathrm{M}] / \mathrm{d} t$ vs. [M]. $k_{r} / k_{d}$ values were calculated from plots of $-\mathrm{d}[\mathrm{C}] / \mathrm{d} t v s . k_{\varepsilon}$ (Figure 2) and $-\mathrm{d}[\mathrm{C}] / \mathrm{d} t$ vs. I (Figure 3). The $k_{p} \cdot k_{r} / k_{t}$ values are low in keeping with the proposition of Dainton ${ }^{16}$, et al., that the propagation velocity of methacrylamide is very low. At low intensities of light used at $\lambda=405 \mathrm{~m} \mu$, the value of $k_{p} \cdot k_{r} / k_{t}$ is still lower than those at other wave lengths, showing that $k_{t}$ increases with decreasing intensity of light. Dainton and Sisley ${ }^{16}$ reported for methacrylamide polymerization, $k_{p} / k_{t}=4.85 \times 10^{-5}$.

Acknowledgement. We thank Dr. K. Venkatarao, formerly of this laboratory, for helpful discussions. We are grateful to the Rohm and Haas Company, Penn., U.S.A., for having forwarded us a gift sample of methacrylamide by airfreight.

\section{REFERENCES}

1. F. Basolo and R. G. Pearson, "Mechanisms of Inorganic Reactions', John Wiley \& Sons, Inc., New York, N.Y., 1958, p 368.

2. A. W. Adamson, W. L. Waltz, E. Zinato, D. W. Watts, P. D. Fleischauer, and R. D. Lindholm, Chem. Rev., 541 (1968).
3. M. G. Evans, M. Santappa, and N. Uri, J. Polym. Sci., 7, 243 (1951).

4. L. V. Natarajan and M. Santappa, J. Polym. Sci., Part A-1, 6, 3245-3257 (1968).

5. L. V. Natarajan and M. Santappa, Polym. Letters, 5, 357-360 (1967).

6. M. Santappa and L.V. Natarajan, "Proceedings of the Indian Academy of Sciences," Vol. LXIX, No. 4, Ser. A, Indian Academy of Sciences, Bangalore, India 1969, pp 284-290.

7. G. A. Delzenne, J. Polym. Sci., Part C, 16, 1027 (1967).

8. E. J. Bowen, "Chemical Aspects of Light," Oxford Univ. Press, London, 1946, p 279.

9. M. Linhard, M. Weigel, and H. Flygare, $Z$. anorg. allgem. Chem., 263, 233 (1951).

10. G. Schwarzenbach, "Complexometric Titrations", Methuen \& Co., London, 1957, p 78.

11. F. S. Dainton and W. D. Sisley, Trans. Faraday Soc., 56, 1369 (1963).

12. C. A. Parker and C. G. Hatchard, Proc. Roy. Soc. (London), A235, 518 (1956).

13. L. F. Fieser, J. Amer. Chem. Soc., 46, 2639 (1924).

14. G. Mino and S. Kaizermann, J. Polym. Sci., 38, 393 (1959).

15. E. Collinson, F. S. Dainton, S. Tazuke, and D. R. Smith, Nature, 198, 26 (1963).

16. F. S. Dainton and W. D. Sisley, Trans. Faraday Soc., 59, 1377 (1963).

17. D. Valentine, Jr., "Advances in Photochemistry" Vol. 6, Interscience, New York, N.Y., 1968.

18. A. W. Adamson, Discussions Faraday Soc., 29, 163 (1960).

19. E. L. Wehry, Quart. Rev., (London), 28, 251 (1967).

20. J. Franck and E. Rabinowitch, Trans. Faraday Soc., 30, 120 (1934).

21. S. Topett, G. A. Delzenne, and G. Smets, J. Polym. Sci., Part A, 2, 1539 (1964).

22. K. Venkatarao and M. Santappa, J. Polym. Sci., Part A-1, 5, 637 (1967).

23. H. Kothandaraman, Ph. D. Thesis, University of Madras, July, 1970. 